\title{
Contribuição do Polo de Apoio Presencial de Juazeiro-BA no processo de ensino-aprendizagem na educação a distância
} Contribution of the Presential Support Pole of Juazeiro - Bahia (Brazil) in the teaching-learning process in distance education

\author{
CAVALCANTE, Kellison Lima Cavalcante. Mestre/Licenciado em Filosofia \\ Instituto Federal de Educação, Ciência e Tecnologia do Sertão Pernambucano - Campus Petrolina. Rua Maria \\ Luiza de Araújo Gomes Cabral, S/N, João de Deus - Petrolina - Pernambuco - Brasil. CEP: 56.316-686 / \\ Telefone: (87) 2101-4300 / E-mail: kellison.cavalcante@ifsertao-pe.edu.br.
}

\section{SILVA, Fernando Roberto Ferreira. Doutor/Licenciado em Ciências Biológicas}

Universidade Estadual do Ceará - Faculdade de Educação, Ciências e Letras de Iguatu. Rua Deoclécio Lima Verde, S/N, Areias - Iguatu - Ceará - Brasil. CEP: 63.500-000/ Telefone: (88) 3581-9455 / E-mail: fernando.roberto@uece.br

\section{RESUMO}

A Educação a Distância tem como principal característica a superação das distâncias física e geográfica e aproximação dos estudantes através da interação por meios tecnológicos. Dessa forma, os Polos de Apoio Presencial da Universidade Aberta do Brasil desempenham importante papel nesse processo de ensino-aprendizagem a distância, como unidades descentralizadas das Instituições de Ensino Superior. Assim, esse trabalho tem como objetivo investigar a importância dos Polos de Apoio Presencial no processo de ensino-aprendizagem na educação a distância através do estudo da contribuição do Polo Juazeiro-BA. Foi realizado através de uma pesquisa exploratória com a aplicação de um questionário aos estudantes de graduação do Polo, para o conhecimento da contribuição do Polo no processo de ensino-aprendizagem. O Polo Juazeiro-BA tem grande importância para a região pela possibilidade de ampliação de oferta de vagas no ensino superior, com cursos nas múltiplas áreas. A sua contribuição estabelece-se pelo apoio e referência aos estudantes rompendo as barreiras da distância física e geográfica, proporcionando possibilidades de ensino, recursos didáticos e tecnológicos, espaços didáticos, orientação pedagógica e motivação para o desenvolvimento da EaD na região.

Palavras-chave: Educação a Distância, Universidade Aberta do Brasil, Apoio Pedagógico.

\begin{abstract}
Distance Education has the main characteristic of overcoming physical and geographical distances and bringing students closer through interaction through technological means. In this way, the Oncampus Support Poles of Universidade Aberta do Brasil play an important role in this process of distance learning and teaching, as decentralized units of Higher Education Institutions. Thus, this work aims to investigate the importance of On-Site Support Poles in the teaching-learning process in distance education through the study of the contribution of Polo Juazeiro-BA. It was carried out through an exploratory research with the application of a questionnaire to undergraduate students at the Polo, to learn about the Polo's contribution to the teaching-learning process. The Polo Juazeiro-BA is of great importance for the region due to the possibility of expanding the offer of places in higher education, with courses in multiple areas. His contribution is established by the support and reference to students breaking the barriers of physical and geographical distance, providing possibilities for teaching, didactic and technological resources, teaching spaces, pedagogical guidance and motivation for the development of Distance Education in the region.
\end{abstract}

Keywords: Distance Education, Open University of Brazil, Pedagogical Support. 
CAVALCANTE, K. L; SILVA, F. R. F.

Contribuição do Polo de Apoio Presencial de juazeiro-BA no processo de ensino-aprendizagem na educação a distância

\section{Introdução}

A Educação a Distância $(E a D)$ é uma modalidade de ensino que possui grande importância e contribuição no sistema educacional em parâmetros nacionais. Sua história é baseada no fortalecimento e avanço das novas tecnologias da informação e comunicação, com uma variedade de ferramentas que proporcionam a interatividade de professores e alunos separados fisicamente no espaço e no tempo. 0 uso dessas novas ferramentas tecnológicas tem possibilitado o sucesso do processo de ensino-aprendizagem a distância.

A EaD evoluiu amparada pelo uso dos recursos tecnológicos e pela descentralização e interiorização das Instituições de Ensino Superior. Dessa forma, a EaD surgiu com a finalidade de democratização do ensino superior, rompendo o isolamento físico e geográfico do aluno, modificando a relação do aluno no contexto habitual da sala de aula. Assim, Xavier (2016) destaca que a EaD socializa e democratiza a educação, amplia as possibilidades do saber, criando e potencializando competências de uma sociedade norteada pela informação.

Nesse sentido, além das tecnologias da informação e comunicação, a modalidade de ensino a distância requer uma equipe multidisciplinar e um espaço físico adequado para o seu desenvolvimento. Assim, ao implantar um curso na modalidade EaD, as instituições públicas de ensino superior devem priorizar a instalação de um Polo de Apoio Presencial, para o desenvolvimento de atividades pedagógicas e administrativas relativas ao curso.

Através da implantação dos Polos de Apoio Presencial, as instituições públicas de ensino superior podem cumprir a missão de expansão e interiorização do ensino superior no Brasil, oportunizando formação de qualidade em todas as regiões do país. De acordo com Santos et al. (2016), o Polo de Apoio Presencial é um espaço que deve privilegiar as ações promovendo situações educacionais e culturais, permitindo que o vínculo entre aluno/polo/universidade seja estabelecido. Assim, oportuniza aos estudantes momentos presenciais de interação e construção de saberes em todo o processo de formação.

De acordo com o Decreto ${ }^{\circ} 9.057$ de 2017 temos que:

Art. 5o 0 polo de educação a distância é a unidade descentralizada da instituição de educação superior, no País ou no exterior, para o desenvolvimento de atividades presenciais relativas aos cursos ofertados na modalidade a distância.

$\S 1^{\circ}$ Os polos de educação a distância manterão infraestrutura física, tecnológica e de pessoal adequada aos projetos pedagógicos dos cursos ou de desenvolvimento da instituição de ensino.

$\S 2$ - São vedadas a oferta de cursos superiores presenciais em instalações de polo de educação a distância e a oferta de cursos de educação a distância em locais que não estejam previstos na legislação. (BRASIL, 2017).

Segundo Ribas, Moreira e Catapan (2011), o Polo de Apoio Presencial consiste em um elemento primordial para a $\mathrm{EaD}$ e para a sua viabilização, pois visa ao acompanhamento, à orientação dos cursistas e a seu desenvolvimento. Possui grande importância e relevância em todo o processo de formação dos estudantes e que de tal maneira é imprescindível o conhecimento do seu 
CAVALCANTE, K. L; SILVA, F. R. F.

Contribuição do Polo de Apoio Presencial de juazeiro-BA no processo de ensino-aprendizagem na educação a distância

papel na EaD. Assim, a pesquisa surge a partir do entendimento da complexidade de formação dos Polos de Apoio Presencial para o desenvolvimento dos cursos de graduação na modalidade EaD e sua importância no processo de ensino-aprendizagem.

Nesse sentido, a escolha da temática de estudo sobre os Polos de Apoio Presencial na Educação a Distância permite questionar situações como: quais as finalidades e contribuições dos polos de apoio presencial no processo de ensino-aprendizagem? Para isso, é necessário observar de que modo a EaD tem ganhado cada vez mais espaço na atualidade, principalmente, pelas suas possibilidades de atuação e pela evolução tecnológica. Assim, a pesquisa foi desenvolvida no Polo de Apoio Presencial de Juazeiro-BA por estar localizado em uma região com grande disponibilidade de oferta de vagas em formação de nível superior, no entanto com crescente demanda de novas oportunidades e ferramentas educacionais.

Dessa forma, suas características de flexibilidade no processo de aprendizagem e pela utilização de uma variedade de ferramentas, tecnologias e metodologias, torna-se fundamental o conhecimento da importância e da contribuição dos Polos de Apoio Presencial no ensino a distância. Assim, essa pesquisa fundamenta-se na investigação da contribuição dada por esses espaços nas formas de ensinar e de aprender, como um espaço educativo.

Nesse contexto a pesquisa fornecerá subsídios para compreensão da importância dos Polos de Apoio Presencial para a manutenção efetiva dos resultados pedagógicos necessários para o desenvolvimento da Educação a Distância no Brasil. Dessa forma, terá como foco de estudo uma análise da implantação e do desenvolvimento do ensino a distância no Polo de Apoio Presencial do sistema Universidade Aberta do Brasil localizado no município de Juazeiro-BA.

\section{Material e métodos}

Com base em uma pesquisa exploratória quantitativa, os dados foram coletados a partir de uma amostragem por acessibilidade. De acordo com Gil (2008) a amostragem por acessibilidade representa o universo de elementos a que o pesquisador tem acesso, admitindo que possam contribuir para a pesquisa. Assim, os dados foram coletados a partir da aplicação de um questionário com estudantes de graduação matriculados nos cursos ofertados pelo Polo de Apoio Presencial de Juazeiro-BA.

O questionário foi desenvolvido na plataforma online Google Forms, com o link enviado em forma de convite e exposição dos objetivos da pesquisa para o correio eletrônico dos estudantes disponibilizado pela Coordenação do Polo. O link foi enviado para um total de 582 correios eletrônicos, alunos matriculados no ano letivo de 2018, com 207 respostas no período da pesquisa. Para Gil (2008), o questionário consiste na técnica de investigação composta por um conjunto de questões que são submetidas a pessoas com o propósito de obter informações. Dessa forma, conforme Google (2017), o uso dos formulários Google permite que o pesquisador recolha e organize gratuitamente informações, sendo as respostas da pesquisa armazenadas em planilhas e podem ser visualizadas em gráficos ou mesmo de forma bruta na planilha.

Dainesi e Goldbaum (2012) afirmam que os questionários enviados via correio eletrônico têm 
CAVALCANTE, K. L; SILVA, F. R. F.

Contribuição do Polo de Apoio Presencial de juazeiro-BA no processo de ensino-aprendizagem na educação a distância

sido cada vez mais utilizado devido à possibilidade de utilizar um link para o questionário e porque os dados são armazenados em um banco de dados. Assim, é possível aliar a comodidade das ferramentas das novas tecnologias da informação e comunicação ao desenvolvimento da pesquisa, possibilitando agilidade no envio e no retorno das respostas por parte dos respondentes.

Para essa pesquisa, as questões perguntadas no questionário referentes a finalidade da frequência, a função do polo, o encontro presencial, colaboração do polo na formação, fator de dificuldade e equipe de tutoria admitiam a possibilidade de escolha de mais de uma alternativa pelos estudantes respondentes. No entanto, prevendo o risco de não incluir alternativas satisfatórias para os respondentes, foi deixado espaço, designado como "outro", para inserção de alternativa na lista. Somente a questão fechada referente ao uso das TICs admitia a escolha apenas de uma alternativa ou a inserção de uma descrição pelo estudante respondente.

Quadro 1 - Questões perguntadas no questionário disponibilizado aos estudantes

\begin{tabular}{|c|l|}
\hline Questão & \multicolumn{1}{c|}{ Pergunta } \\
\hline 1 & Com qual frequência você vai ao Polo de Apoio Presencial? \\
\hline 2 & $\begin{array}{l}\text { Além dos encontros presenciais previstos no Projeto Pedagógico do Curso, com qual } \\
\text { finalidade você frequenta o Polo de Apoio Presencial? }\end{array}$ \\
\hline 3 & Para você, qual a função do Polo de Apoio Presencial? \\
\hline 4 & $\begin{array}{l}\text { O que os encontros presenciais no Polo de Apoio Presencial proporcionam no seu } \\
\text { processo de aprendizagem? }\end{array}$ \\
\hline 5 & $\begin{array}{l}\text { De que forma o Polo de Apoio Presencial colabora para a sua formação acadêmica? } \\
\text { aprendizagem no Polo de Apoio Presencial? }\end{array}$ \\
\hline 7 & $\begin{array}{l}\text { De que forma a atuação da Equipe de Tutoria contribui para a sua formação } \\
\text { acadêmica? }\end{array}$ \\
\hline 8 & $\begin{array}{l}\text { Como você considera o uso dos equipamentos e recursos tecnológicos no seu } \\
\text { processo de aprendizagem? }\end{array}$ \\
\hline 6
\end{tabular}

Fonte: Pesquisa direta.

Após a coleta de dados do questionário foi feita a análise, a partir da organização das respostas obtidas com o auxílio do software livre Tableau Public, resultando na obtenção de quadros e gráficos para visualização dos resultados. Com a organização dos dados em quadros e gráficos foi possível obter respostas à problemática investigada nessa pesquisa.

A interpretação dos dados foi realizada com o objetivo de compreender e dar sentido ao estudo da contribuição do Polo de Apoio Presencial de Juazeiro-BA no processo de ensinoaprendizagem dos estudantes de graduação na modalidade EaD. Assim, a interpretação foi realizada através da organização dos dados obtidos e a inferência das relações e ligações com estudos já desenvolvidos sobre a temática, para dar um sentido mais amplo para as respostas da pesquisa. 
CAVALCANTE, K. L; SILVA, F. R. F.

Contribuição do Polo de Apoio Presencial de juazeiro-BA no processo de ensino-aprendizagem na educação a distância

\section{Resultados e discussão}

Na Educação a Distância, o aluno tem um importante papel no processo de ensinoaprendizagem, que consiste principalmente na responsabilidade de ser o protagonista na busca e construção do conhecimento. Moore e Kearsley (2008) destacam que o aluno da EaD é responsável pela organização de tempo para a efetivação da aprendizagem, no desenvolvimento da autonomia, no conhecimento básico de informática e no relacionamento e interação com os outros alunos. 0 aluno torna-se envolvido em todo o processo de ensino-aprendizagem na EaD, capaz de dar maior significado à aprendizagem e à apropriação do conhecimento.

Para o desenvolvimento educacional nessa modalidade de ensino, torna-se essencial o conhecimento de sua frequência ou participação em atividades desenvolvidas no Polo de Apoio Presencial. Dessa forma, o conhecimento da periodicidade que os estudantes frequentam o Polo Juazeiro-BA colabora na efetivação de atividades didáticas e pedagógicas, para que seja possível compreender a relação do Polo na formação acadêmica. De acordo com os dados do Gráfico 1, é possível observar que, no período de um mês, 35,27\% dos estudantes frequentam pelo menos 1 vez o Polo, $31,88 \%$ a cada 15 dias, $12,08 \%$ uma vez por semana e $0,97 \%$ diariamente. Assim, esses estudantes representam $80,20 \%$ que frequentam pelo menos uma vez por mês o Polo Juazeiro-BA.

Gráfico 1 - Periodicidade que os estudantes frequentam o Polo Juazeiro-BA

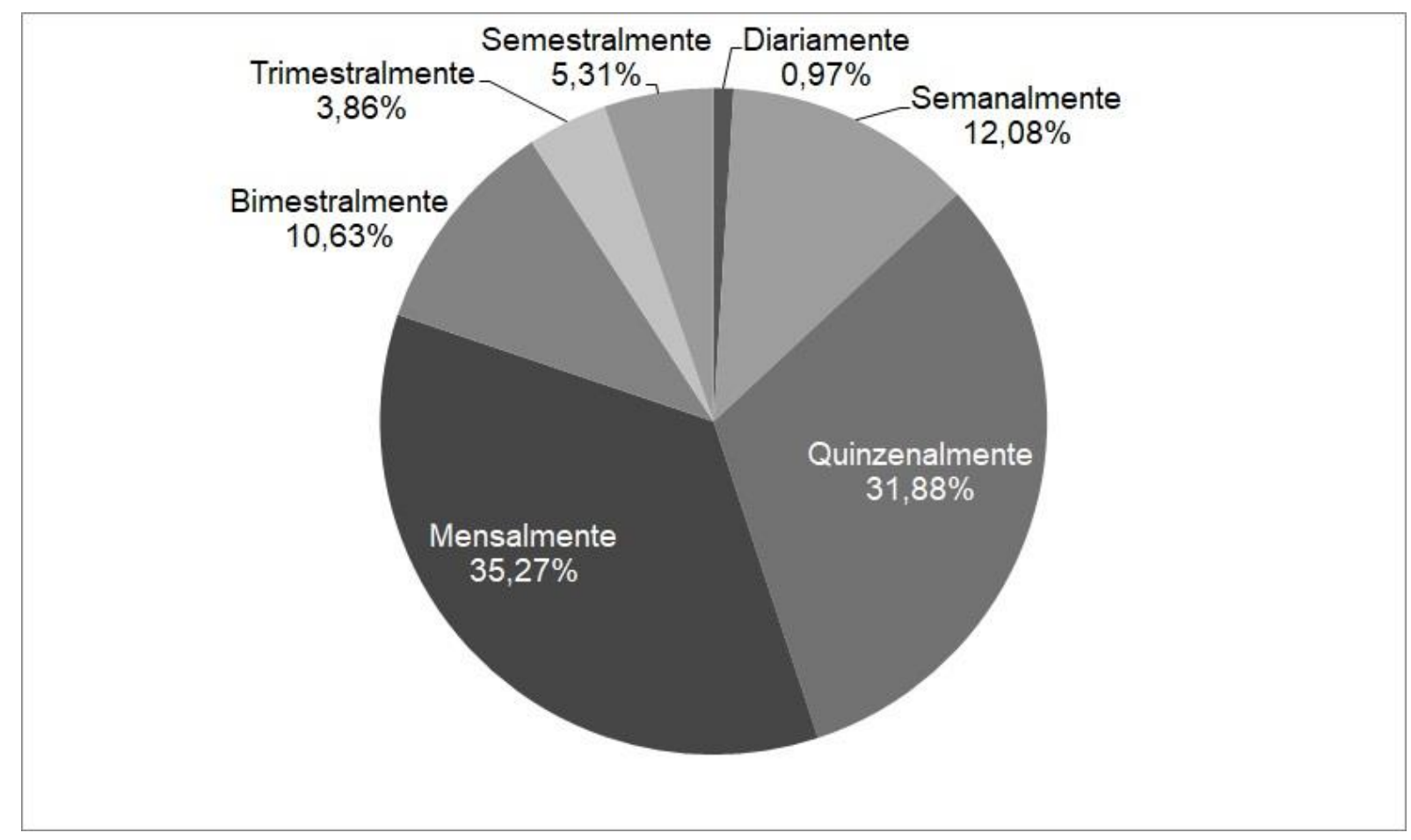

Fonte: Questionário aplicado aos estudantes do Polo Juazeiro-BA.

Nessa perspectiva, Moore e Kearsley (2013) ressaltam que a frequência nos Polos de Apoio Presencial torna o aluno envolvido em todo o processo de ensino-aprendizagem na EaD, capaz de dar maior significado a aprendizagem e conhecimento. Assim, o conhecimento dessa frequência 
CAVALCANTE, K. L; SILVA, F. R. F.

Contribuição do Polo de Apoio Presencial de juazeiro-BA no processo de ensino-aprendizagem na educação a distância

torna-se importante para o planejamento da Coordenação do Polo, para melhor atender os seus estudantes.

Conhecendo a frequência dos estudantes de graduação do Polo Juazeiro-BA, é imprescindível investigar a finalidade dessa frequência e buscar entender como ocorre essa relação no seu processo de aprendizagem na EaD. Nesse sentido, García Aretio (2017) ressalta que a abertura e a oferta de cursos na EaD são alcançadas através da flexibilidade no tempo e no espaço, com a eficiência na integração de mídias e de recursos no processo de aprendizagem. Assim, no Gráfico 2 é possível compreender a finalidade que os estudantes frequentam o Polo Juazeiro-BA.

Gráfico 2 - Finalidade da frequência dos estudantes no Polo Juazeiro-BA

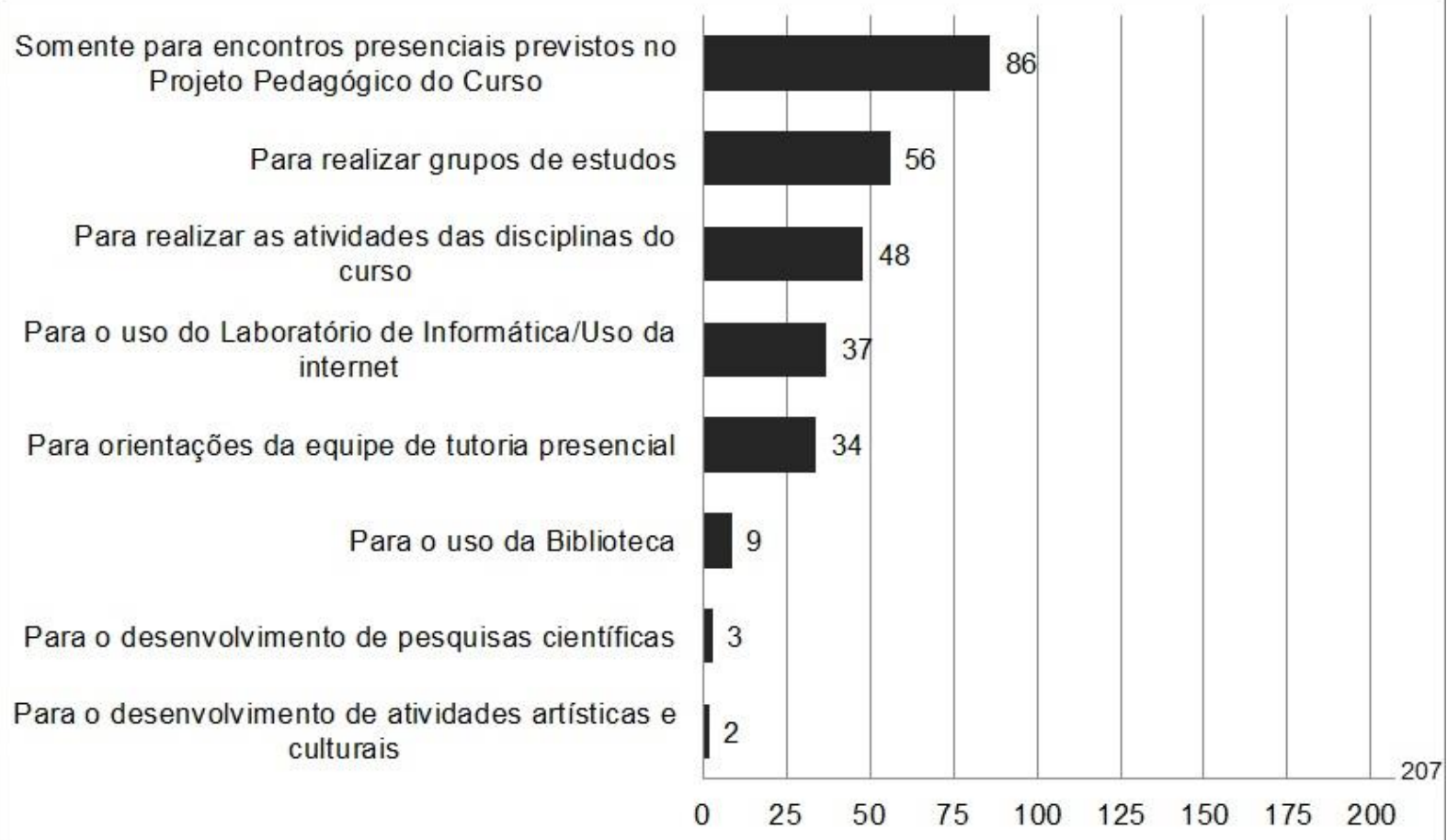

Fonte: Questionário aplicado aos estudantes do Polo Juazeiro-BA.

Diante disso, observa-se um cenário bem diversificado de finalidades de frequência ao Polo, com 86 estudantes destacando a frequência somente para os encontros presenciais previstos no Curso. Dessa forma, demonstra-se a importância dos encontros presenciais na formação acadêmica dos estudantes de EaD. No entanto, destaca-se a frequência ao Polo, além dos encontros presenciais, para realizar grupos de estudos (56), para realizar atividades das disciplinas do curso (48), para o uso do Laboratório de Informática e uso da Internet (37) e para orientações da equipe de tutoria (34).

Para Ribeiro, Timm e Zaro (2007), os Polos de Apoio Presencial da EaD são constituídos para os estudos como um ponto de referência institucional que norteie e agregue os recursos de planejamento e desenvolvimento da educação a distância, com critérios claros de planejamento e gestão, bem como instrumentos para acompanhar e coordenar cada etapa do trabalho. Assim, o Polo Juazeiro-BA, através de suas ações de planejamento e gestão, contribui de forma efetiva na 
CAVALCANTE, K. L; SILVA, F. R. F.

Contribuição do Polo de Apoio Presencial de juazeiro-BA no processo de ensino-aprendizagem na educação a distância

participação dos estudantes na construção do conhecimento e de uma formação de qualidade. Dessa forma, no Gráfico 3 destaca-se a compreensão dos estudantes de graduação sobre a função do Polo de Apoio Presencial.

Gráfico 3 - Compreensão sobre a função do Polo de Apoio Presencial na EaD

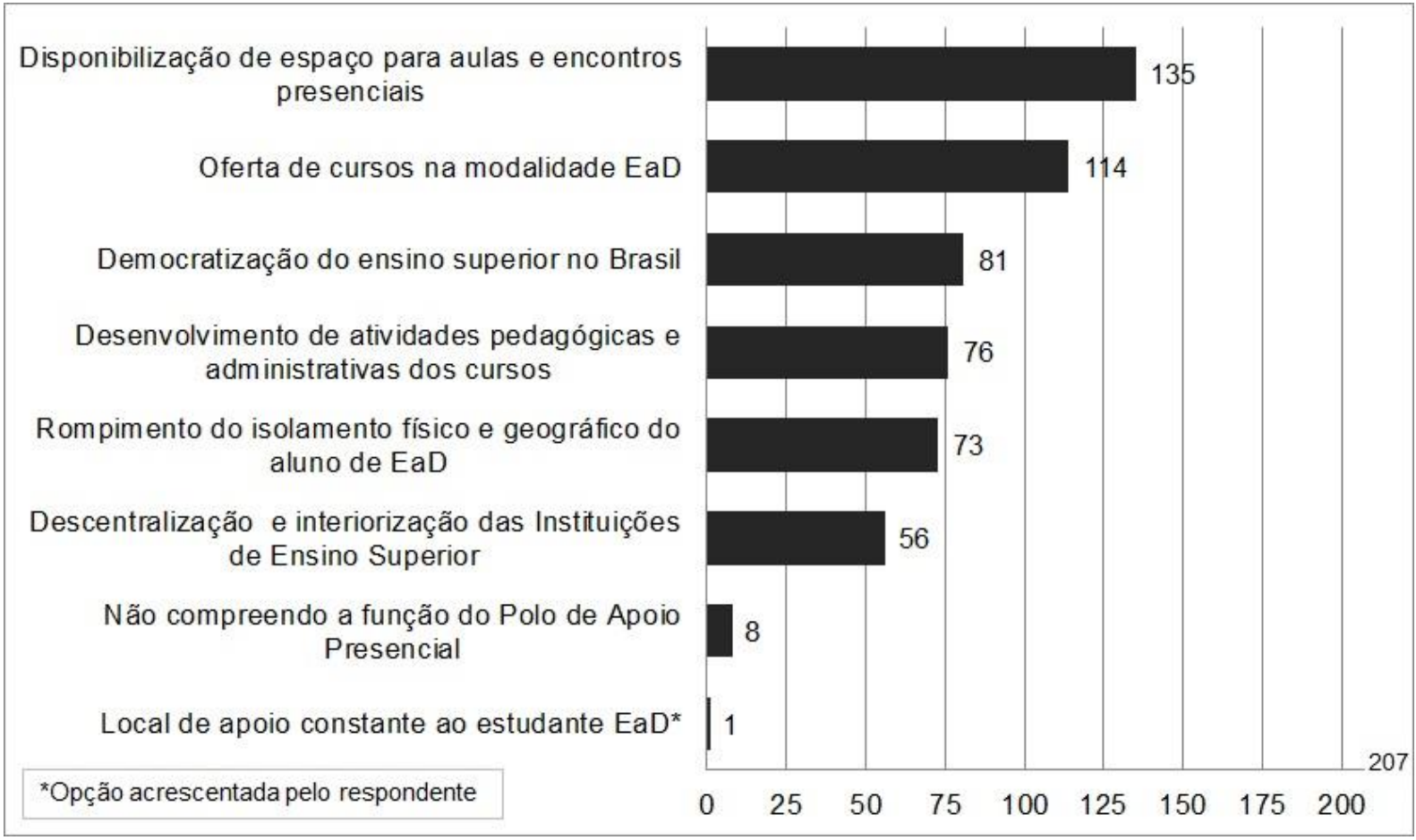

Fonte: Questionário aplicado aos estudantes do Polo Juazeiro-BA.

Os estudantes de graduação do Polo Juazeiro-BA destacaram a disponibilização de espaço para aulas e encontros presenciais (135) seguida da oferta de cursos na modalidade EaD (114) como as principais funções de um Polo de Apoio Presencial. Para Santos et al. (2016), o polo de apoio presencial é um espaço que deve privilegiar as ações promovendo situações educacionais e culturais, permitindo que o vínculo entre aluno/polo/universidade seja estabelecido. Nesse sentido, os estudantes ainda destacaram a democratização do ensino superior (81), desenvolvimento de atividades pedagógicas e administrativas (76), rompimento do isolamento físico e geográfico (73) e a descentralização e interiorização das IES (56), representando que os estudantes compreendem o Polo com funções importantes para o desenvolvimento e avanço da EaD no Brasil.

Nesse cenário, apenas 8 estudantes pesquisados destacam que não compreendem a função de um Polo de Apoio Presencial, podendo até mesmo atrelarem sua função a extensão da IES que estão matriculados. No entanto, um estudante pesquisado inseriu a função de local de apoio constante ao estudante. Horta (2009) destaca a importância do Polo de Apoio Presencial para a garantia efetiva dos resultados pedagógicos.

A partir dessa discussão, é possível inferir que mesmo com o uso e avanço das novas TICs, a EaD ainda prioriza a importância das relações estabelecidas principalmente através dos encontros presenciais. Para Alves, Mari e Freire (2013) os encontros presenciais influem positivamente na 
CAVALCANTE, K. L; SILVA, F. R. F.

Contribuição do Polo de Apoio Presencial de juazeiro-BA no processo de ensino-aprendizagem na educação a distância

qualidade das aprendizagens que se realizam, pois estreitam as relações entre as pessoas e entre essas e as IES. Dessa forma, no Gráfico 4 encontramos o que os estudantes pesquisados identificam nos encontros presenciais, como forma de contribuição no seu processo de formação acadêmica.

Gráfico 4 - Os encontros presenciais no Polo Juazeiro-BA

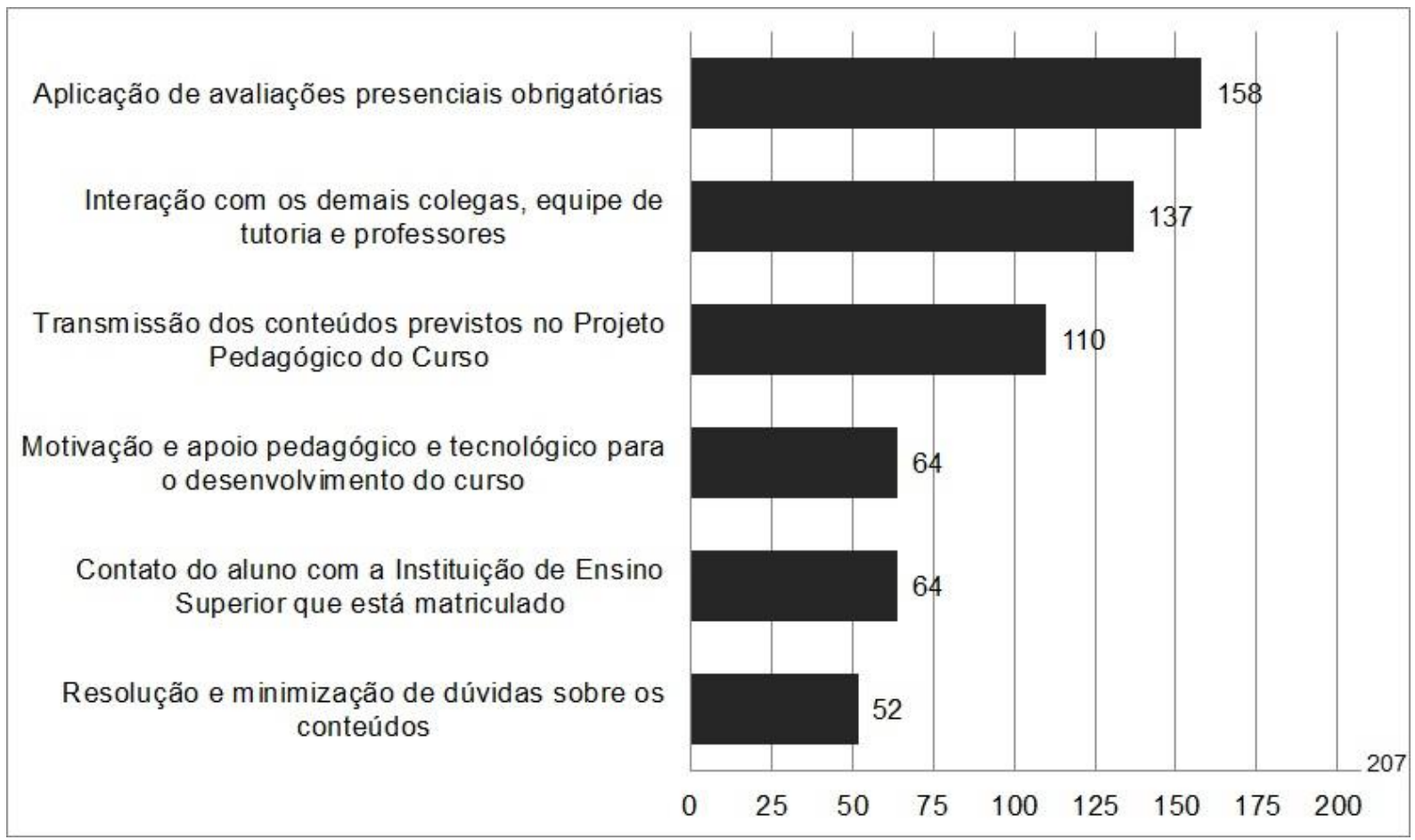

Fonte: Questionário aplicado aos estudantes do Polo Juazeiro-BA.

Segundo Netto (2010), os encontros presenciais propiciam que os estudantes se sintam mais motivados, desenvolvendo maior facilidade de aprendizagem através do aspecto afetivo como um dos elementos importantes que deve ser considerado no processo de aprendizagem. Assim, 158 estudantes pesquisas ressaltam a importância dos encontros presenciais no Polo Juazeiro-BA para a aplicação de avaliações presenciais obrigatórias. Já 137 estudantes destacam a interação com todos os envolvidos na EaD como a contribuição do encontro presencial na sua formação. Dessa forma, as relações afetivas são destacadas no seu processo educativo, implicando a interação como uma relação na construção coletiva e colaborativa na $\mathrm{EaD}$. Dessa forma, a transmissão de conteúdos que envolve o processo de ensino-aprendizagem foi destacada por 110 estudantes como uma forma de contribuição dos encontros presenciais.

Nesse sentido, Alves, Mari e Freire (2013) ressaltam que os encontros presenciais na EaD são ricos em trocas de relações, experiências, valores, afetividade e que qualificam o processo e uma aprendizagem significativa na formação dos estudantes. A partir desses encontros presenciais e da participação efetiva do estudante na construção do seu conhecimento na EaD, o Gráfico 5 identifica as principais formas de colaboração do Polo Juazeiro-BA na formação acadêmica dos estudantes de graduação. 
CAVALCANTE, K. L; SILVA, F. R. F.

Contribuição do Polo de Apoio Presencial de juazeiro-BA no processo de ensino-aprendizagem na educação a distância

Gráfico 5 - O Polo Juazeiro-BA no processo de formação acadêmica

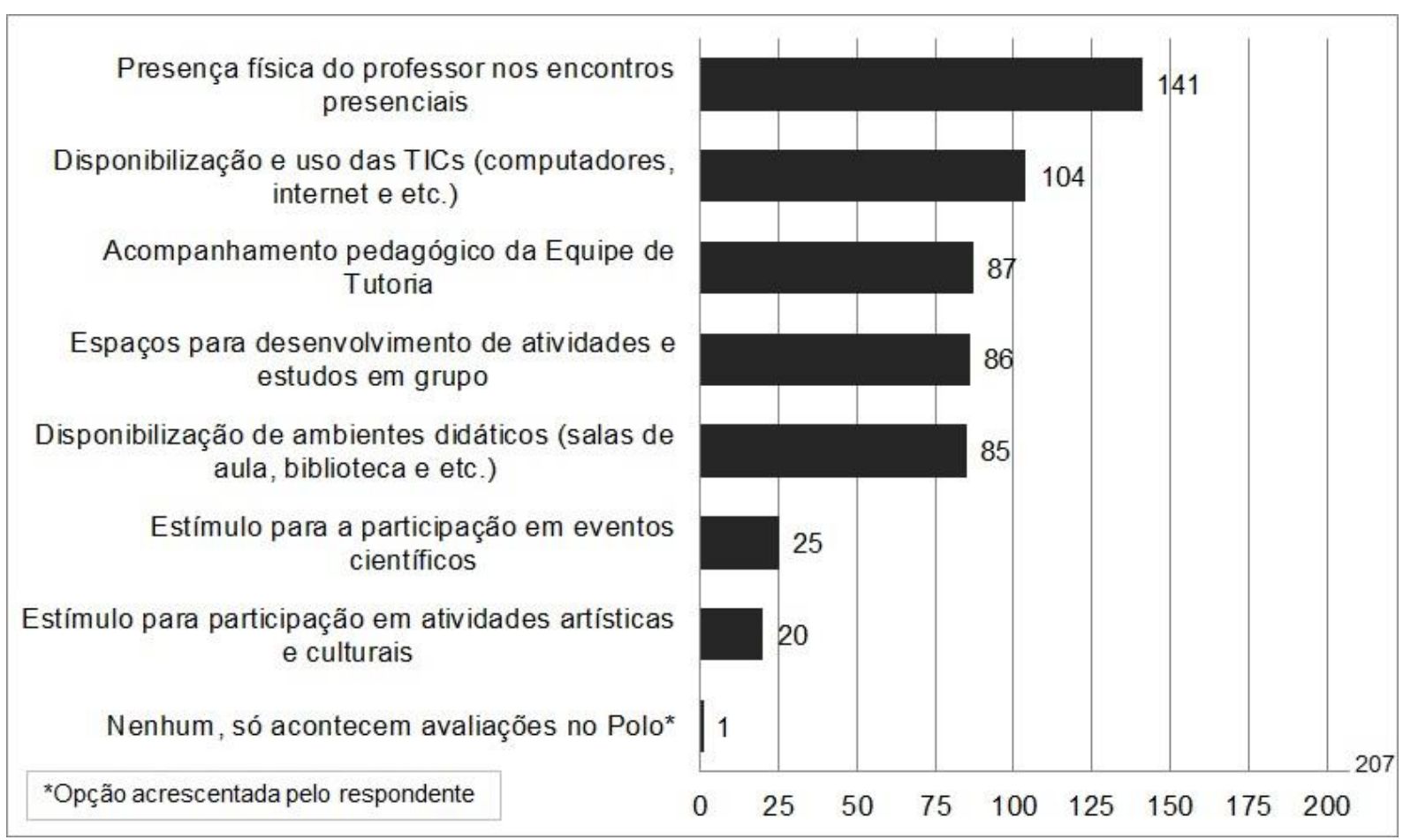

Fonte: Questionário aplicado aos estudantes do Polo Juazeiro-BA.

Para a maioria dos estudantes pesquisados, 141 destacaram a presença física do professor nos encontros presenciais e 104 a disponibilização e uso das TICs no processo de ensinoaprendizagem como forma de colaboração do Polo Juazeiro-BA na sua formação. Assim, os dados mostram a importância do conhecimento mediado pela presença do professor, potencializando as interações entre os estudantes, professores, tutores e Polo de Apoio Presencial. Destacando ainda a atuação da equipe de tutoria (87), o espaço para realização de atividades e estudos em grupos (86) e os ambientes didáticos (85) como formas de contribuição do Polo Juazeiro-BA na formação acadêmica dos estudantes.

Para o Ministério da Educação (2007) os Polos de Apoio Presencial desempenham papel de grande importância para a educação a distância, contribuindo para o desenvolvimento dos cursos ofertados por IES parceiras e funciona como um ponto de referência fundamental para o estudante. o Polo Juazeiro-BA, na visão dos estudantes, oferece recursos e meios para o fortalecimento e construção da aprendizagem durante a formação acadêmica, como forma de descentralização do ensino e apoio ao desenvolvimento educacional.

No entanto, devem-se destacar as particularidades que podem dificultar ou criar barreias para o processo de ensino-aprendizagem no Polo Juazeiro-BA, conforme dados do Gráfico 6, e assim procurar melhorias. Para o Ministério da Educação (2007), torna-se imprescindível o conhecimento de fatores que dificultam o avanço da EaD e devem respeitar as peculiaridades de cada região e localidade, bem como as particularidades dos cursos ofertados. 
CAVALCANTE, K. L; SILVA, F. R. F.

Contribuição do Polo de Apoio Presencial de juazeiro-BA no processo de ensino-aprendizagem na educação a distância

Gráfico 6 - Fatores de dificuldade no processo de ensino-aprendizagem

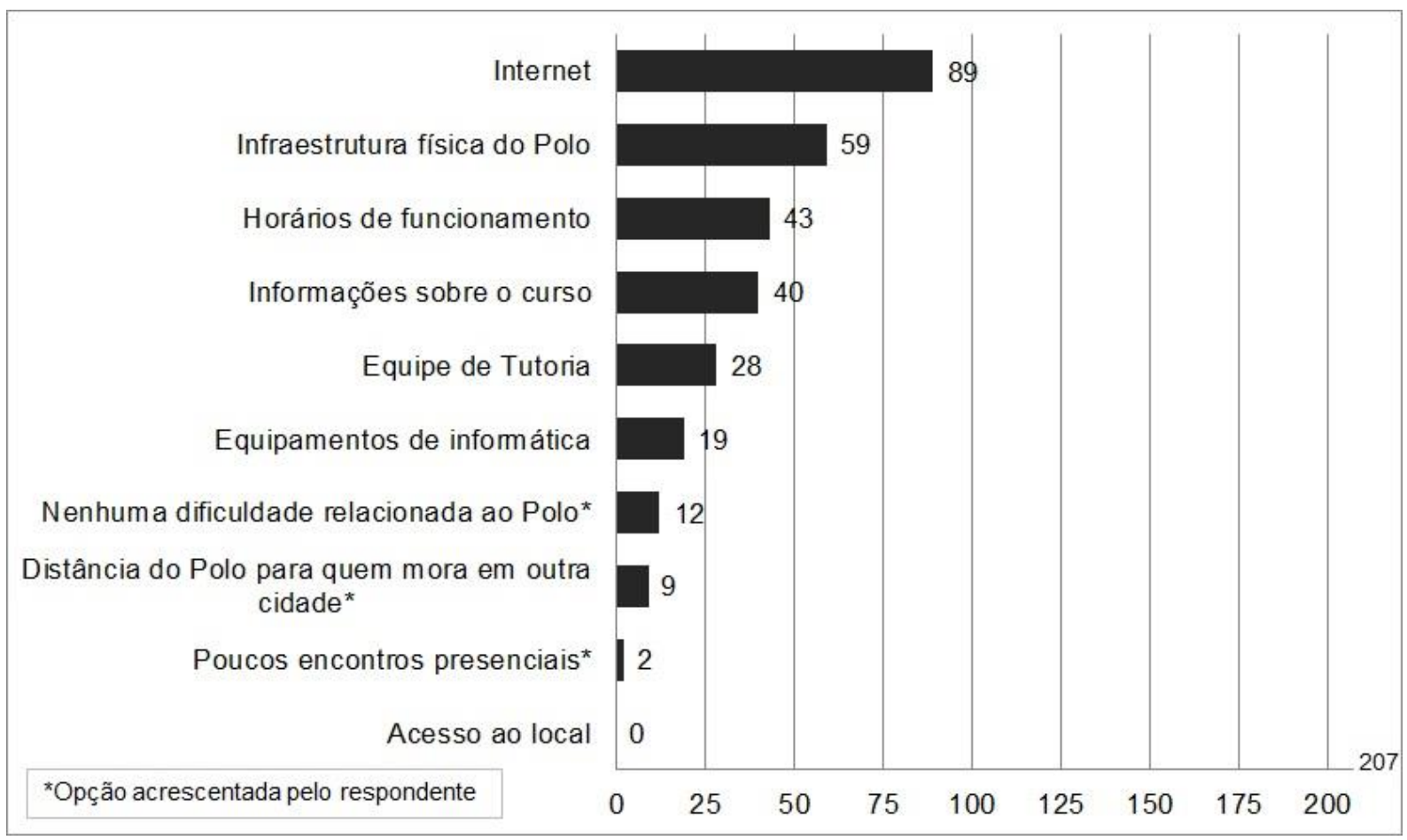

Fonte: Questionário aplicado aos estudantes do Polo Juazeiro-BA.

Nesse cenário, os estudantes destacaram grande variação de fatores que dificultam o processo de ensino-aprendizagem no Polo Juazeiro-BA, principalmente o acesso a Internet, escolhido por 89 estudantes pesquisados. A infraestrutura física do Polo, apontada por 59 estudantes pesquisados, pode ser entendida pela disponibilidade de salas de aula devido a grande demanda de cursos ofertados. No entanto, segundo a Coordenação do Polo Juazeiro-BA, não há problema na realização dos encontros presenciais previstos por cada curso, seguindo cronograma e roteiros definidos previamente.

Merecem destaque os fatores de dificuldade acrescentados pelos estudantes pesquisados: distância do Polo para quem mora em outra cidade (9), tendo em vista que o Polo Juazeiro-BA abrange uma quantidade expressiva de municípios do Estado da Bahia, incluindo ainda estudantes residentes em nos Estados de Pernambuco e até de Santa Catarina; e poucos encontros presenciais (2), sendo uma responsabilidade das Coordenações de cada curso e seus respectivos Projetos Políticos Pedagógicos (PPP). Informações sobre o curso (40) e equipe de tutoria (28), segundo a Coordenação do Polo Juazeiro-BA, também são de responsabilidade das Coordenações de cada curso.

Para o acompanhamento, mediação e superação de dificuldades, a equipe de tutoria desempenha papel importante na promoção da interação entre aluno, professor, instituição de ensino que está matriculado e o Polo de Apoio Presencial, proporcionando condições para o desenvolvimento e potencialização das capacidades dos estudantes. Conforme Prado et al. (2012) acredita-se que a tutoria tem papel fundamental na Educação a Distância, pois garante uma relação personalizada e contínua do estudante no sistema e viabiliza a articulação necessária entre os 
CAVALCANTE, K. L; SILVA, F. R. F.

Contribuição do Polo de Apoio Presencial de juazeiro-BA no processo de ensino-aprendizagem na educação a distância

elementos do processo e execução dos objetivos propostos. Assim, a tutoria é essencial para o desenvolvimento e desempenho da $\mathrm{EaD}$, presente na interação professor-aluno, comunicação, avaliação e mediação.

De acordo com o Gráfico 7, observamos dados referentes à atuação da equipe de tutoria do Polo Juazeiro-BA no desenvolvimento da EaD dos cursos ofertados. Dessa forma, para 112 estudantes pesquisados, a equipe de tutoria envolve o desenvolvimento e acompanhamento de ações pedagógicas, que têm como finalidade despertar a autonomia e responsabilidade dos alunos na construção do conhecimento, mediando o uso de ferramentas tecnológicas e a interação social. A atuação da tutoria tem grande relação com o planejamento, a metodologia e a avaliação dos alunos em todo o processo de ensino-aprendizagem. Essa relação dinâmica resulta na importância da tutoria no processo de mediação, evidenciando a parceria entre o docente, equipes pedagógica e administrativa e alunos.

Gráfico 7 - A equipe de tutoria do Polo Juazeiro-BA

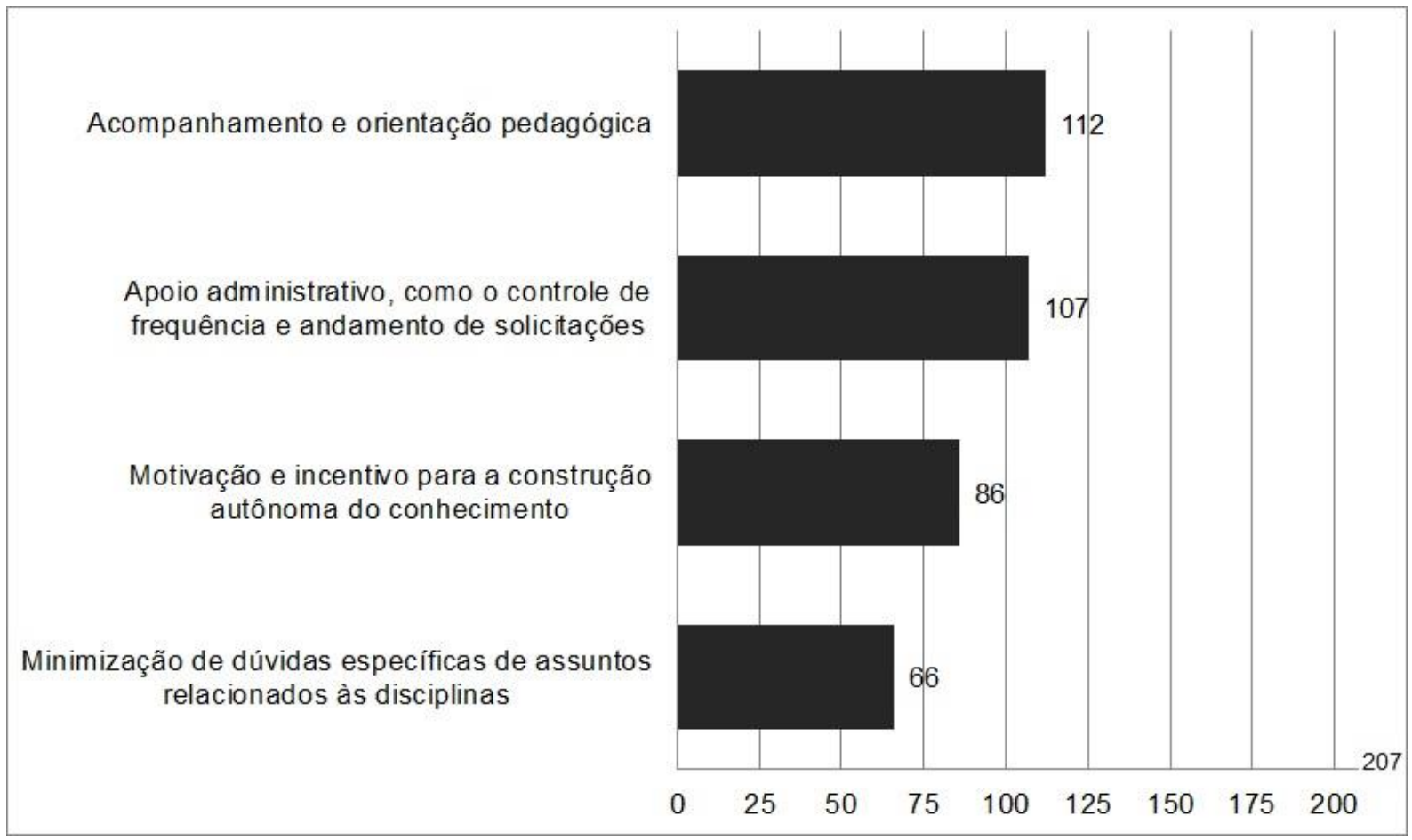

Fonte: Questionário aplicado aos estudantes do Polo Juazeiro-BA.

A tutoria compreende uma atuação ativa e permanente da prática pedagógica mediada por meio de tecnologias. A tutoria permeia a missão de orientar e mediar as atividades dos estudantes na EaD, atuando em todo o processo que constitui essa modalidade. De acordo com Pacheco e Sardinha (2015) a tutoria na EaD atua como responsável pela disseminação do conhecimento e criação de um ambiente motivador. Nessa atuação, torna-se fundamental a orientação e a direção da construção do conhecimento pelos alunos. Tornando-se a tutoria responsável pelo gerenciamento de condições pedagógicas satisfatórias para a aprendizagem dos alunos, apoiando o professor da disciplina no desenvolvimento das atividades que foram planejadas. 
CAVALCANTE, K. L; SILVA, F. R. F.

Contribuição do Polo de Apoio Presencial de juazeiro-BA no processo de ensino-aprendizagem na educação a distância

Conforme Mendes (2016), a partir da tutoria, o estudante tem a capacidade de desenvolver o seu papel na EaD de forma ativa e participativa, tornando-se capaz de construir sua aprendizagem autônoma. A tutoria tem a importância de mediar e orientar o melhor caminho em busca da aprendizagem que possibilite ao estudante o apoio para assumir uma postura autônoma e independente.

Diante da motivação e orientação pela equipe de tutoria para a construção autônoma do conhecimento na EaD, os estudantes têm as Tecnologias da Informação e Comunicação (TICs) como ferramentas essenciais no processo de ensino-aprendizagem. 0 Gráfico 8 destaca como ocorre o uso das TICs pelos estudantes do Polo Juazeiro-BA.

Gráfico 8 - 0 uso das Tecnologias da Informação e Comunicação no Polo Juazeiro

Uso computadores, internet e demais recursos tecnológicos do Polo de Juazeiro apenas quando tenho encontro presencial

Além do uso nos encontros presenciais, frequento

o Polo em outros horários para usar computadores, internet e demais recursos tecnológicos

Opção acrescentada pelo respondente
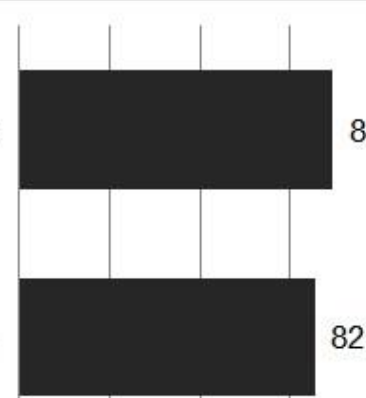

82

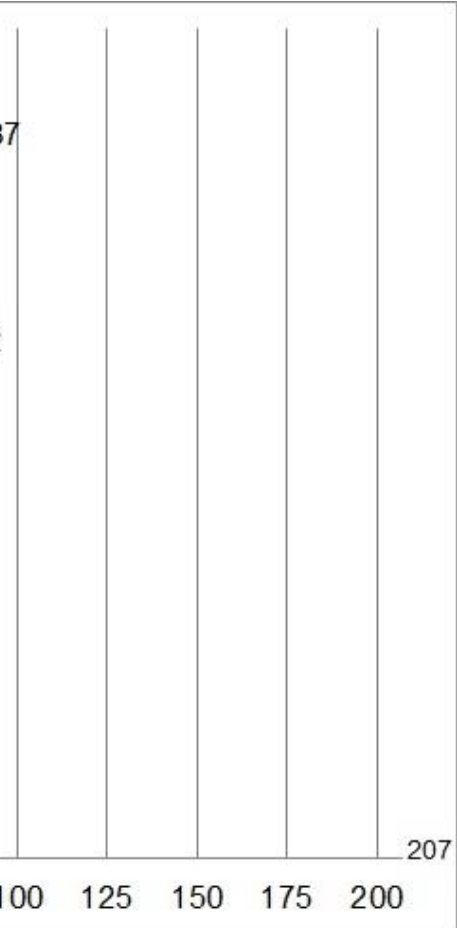

Fonte: Questionário aplicado aos estudantes do Polo Juazeiro-BA.

De acordo com os dados obtidos, 87 estudantes do Polo Juazeiro-BA usam as TICs somente em suas casas. No entanto, parcela bem próxima dos estudantes (82) usam computadores, internet e demais recursos tecnológicos do Polo Juazeiro-BA apenas quando possuem encontros presenciais. Já 34 estudantes frequentam o Polo para uso das TICs em momentos além dos encontros presenciais. Nesse sentido, García Aretio (2017) considera a Educação a Distância como um fenômeno disruptivo, provocando a alteração do modo de ensinar presencial e evoluindo através das novas tecnologias e inovações. Assim, substitui a forma de ensino tradicional e utiliza novos produtos a serviço da aprendizagem. 
CAVALCANTE, K. L; SILVA, F. R. F.

Contribuição do Polo de Apoio Presencial de juazeiro-BA no processo de ensino-aprendizagem na educação a distância

\section{Conclusões}

A Educação a Distância (EaD) tem contribuído cada vez mais para o desenvolvimento do cenário educacional brasileiro, através da oferta de cursos com qualidade e para uma demanda maior de estudantes e distintos perfis. Dessa forma, a EaD tem como principal característica a superação das distâncias física e geográfica e aproximação dos estudantes através da interação por meios tecnológicos. Assim, a EaD evoluiu, amparada pelas ferramentas oferecidas pelas novas Tecnologias da Informação e Comunicação (TIC), pela sua estrutura multidisciplinar e por infraestruturas físicas descentralizadas das Instituições de Ensino Superior (IES), através dos Polos de Apoio Presencial, possibilitando a construção autônoma do conhecimento dos estudantes e a mediação pedagógica da informação.

Nesse sentido, o Polo de Apoio Presencial de Juazeiro-BA representa a descentralização de IES, que mesmo distantes geograficamente, ofertam cursos na modalidade EaD para a região Juazeiro-BA e Petrolina-PE, conforme estudo realizado. Assim, tem grande importância pela possibilidade de ampliação de oferta de vagas no ensino superior para os estudantes da região, compreendendo múltiplas áreas de formação e diversidades de contextos de perfis dos educandos.

Dessa forma, a partir dos dados coletados, observa-se que $80,20 \%$ dos estudantes pesquisados frequentam o Polo Juazeiro-BA pelo menos uma vez por mês. Assim, diante de toda a demanda, o Polo Juazeiro-BA representa uma diversidade de estudantes que procuram apoio, orientação e espaços para a construção do conhecimento na EaD. Assim, os estudantes frequentam o referido Polo não somente para os encontros presenciais, como também para o uso dos espaços, das TICs e para a construção do conhecimento. Destacando a importância dos encontros presenciais para a aplicação de avaliações e interação entre alunos, professores e demais agentes da EaD. Para isso, o Polo tem papel fundamental na formação acadêmica com a presença dos professores, disponibilização das TICs, atuação da equipe de tutoria e dos demais espaços do Polo. No entanto, os estudantes ressaltam o serviço de Internet como um fator limitante no processo de ensinoaprendizagem, fundamental para o desenvolvimento de atividades e avanço da EaD.

O Polo de Apoio Presencial de Juazeiro-BA contribui para a formação acadêmica da região de Juazeiro-BA e Petrolina-PE, com importante papel no desenvolvimento e avanço da EaD. Assim, sua contribuição estabelece-se pela possibilidade de interação e interatividade no processo de ensinoaprendizagem, rompendo as barreiras da distância física e geográfica e aproximando estudantes da educação de qualidade, proporcionando possibilidades de ensino, recursos didáticos e tecnológicos, espaços didáticos, orientação pedagógica e motivação para o desenvolvimento da $\mathrm{EaD}$ na região.

\section{Referências}

ALVES, J. N.; MARI, I.; FREIRE, F. G. Encontro presencial no ensino a distância: possibilidades e fronteiras. Fasci-Tech, São Caetano do Sul, v. 1, n. 7, p. 53-66, mar./set., 2013.

BRASIL. Decreto $\mathrm{n}^{\circ} \mathbf{9 . 0 5 7}$, de 25 de maio de 2017. Regulamenta o art. 80 da Lei $n=9.394$, de 20 de 
CAVALCANTE, K. L; SILVA, F. R. F.

Contribuição do Polo de Apoio Presencial de juazeiro-BA no processo de ensino-aprendizagem na educação a distância

dezembro de 1996, que estabelece as diretrizes e bases da educação nacional. Disponível em: <http://www.planalto.gov.br/ccivil_03/_Ato2015-2018/2017/Decreto/D9057.htm\#art24>. Acesso em: 07 out. 2017.

DAINESI, S. M.; GOLDBAUM, M. Pesquisa clínica como estratégia de desenvolvimento em saúde. Rev. Assoc. Med. Bras., v. 58, n. 1, p. 2-6, 2012.

GARCÍA ARETIO, L. Educación a distancia y virtual: calidad, disrupción, aprendizajes adaptativo y móvil. RIED. Revista Iberoamericana de Educación a Distancia, Madri, v. 20, n. 2, p. 09-25, 2017.

GIL, A. C. Métodos e técnicas de pesquisa social. 6. ed. São Paulo: Atlas, 2008.

GOOGLE. Clear Google Drive space \& increase storage. 2017. Disponível em: <https://support.google.com/drive/answer/6374270?src=soctw>. Acesso em: 18 Jun. 2018.

HORTA, S. D. P. A influência da estrutura física no ensino aprendizado. 2009.

Disponível em< http://www.webartigos.com/artigos/a-influencia-da-estrutura-fisica-noensinoaprendizado/28413/>. Acesso em 17 Jun. 2018.

MENDES, A. N. A importância da tutoria na Educação a Distância. Educação a Distância, Batatais, v. 6, n. 1, p. 109-122, jan./jun. 2016.

MINISTÉRIO DA EDUCAÇÃO. Secretaria de Educação a Distância. Referenciais de qualidade para educação superior a distância. Brasília, 2007. Disponível em: < http://portal.mec.gov.br/seed/arquivos/pdf/legislacao/refead1.pdf>. Acesso em 27 Jul. 2018.

MOORE, M; KEARSLEY, G. Educação a distância: uma visão integrada. 2. ed. São Paulo: Cengage Learning, 2008. $418 \mathrm{p}$.

MOORE, M; KEARSLEY, G. Educação a distância: sistemas de aprendizagem online. 3. ed. São Paulo: Cengage Learning, 2013.

NETTO, C. M. Estratégias para construção de relações afetivas em ambientes virtuais de aprendizagem. $2010 . \quad$ Disponível em: http://www.abed.org.br/congresso2010/cd/252010085045.pdf>. Acesso em: 07 Jul. 2018.

PACHECO, F.; SARDINHA, P. C. D. A importância do tutor em ambientes de ensino-aprendizagem e ferramentas de avaliação em EaD. Comunicação \& Mercado, Dourados, v. 4, n. 10, p. 142-150, jul./dez. 2015. 
CAVALCANTE, K. L; SILVA, F. R. F.

Contribuição do Polo de Apoio Presencial de juazeiro-BA no processo de ensino-aprendizagem na educação a distância

PRADO, C; CASTELI, C. P. M.; LOPES, T. O.; KOBAYASHI, R. M.; PERES, H. H. C.; LeITE, M. M. J. Espaço virtual de um grupo de pesquisa: o olhar dos tutores. Revista Esc. Enferm., São Paulo: USP, v. 46, n. 1, p. 246-251, 2012.

RIBAS, J. C. C.; MOREIRA, B. C. M.; CATAPAN, A. H. Construindo referenciais de qualidade para uma gestão eficaz no Sistema Universidade Aberta do Brasil: o ambiente virtual de ensino-aprendizagem e a capacitação dos coordenadores de polo de apoio presencial. In: CONGRESSO INTERNACIONAL ABED DE EDUCAÇÃO A DISTÂNCIA, 17., 2011. Manaus. Anais... Florianópolis: ABED, 2011.

RIBEIRO, L. O. M.; TIMM, M. I.; ZARO, M. A. Gestão de EaD: a importância da visão sistêmica e da estruturação dos CEADs para a escolha de modelos adequados. CINTED-UFRGS, v. 5. n. 1, jul. 2007.

SANTOS, A. A. S.; FAGUNDES, A. I. J.; OLIVEIRA, C. G.; COSTA, S. G. Avaliação de pólos de apoio presencial de ead: um estudo comparado. In: SIMPÓSIO INTERNACIONAL DE EDUCAÇÃO A DISTÂNCIA, 3., 2016. São Carlos. Anais... São Carlos: UFSCar, 2016.

XAVIER, M. A. G. A gestão pública do sistema da Universidade Aberta do Brasil: estudo de caso no polo de apoio presencial em Resende. EaD em Foco, Rio de Janeiro, v. 6, n. 1, 2016. 